\title{
Hydrothermally synthesized Nickel cobalt oxide for bifunctional electrochemical supercapacitor and nonenzymatic glucose biosensor
}

O. C. Pore

Lal Bahadur Shastri College of Arts, Science and Commerce, Satara

A. V. Fulari

Dongguk University

V. J. Fulari

Shivaji University

G. M. Lohar ( $\nabla$ gauravlohar24@gmail.com )

Lal Bahadur Shastri College of Arts, Science and Commerce, Satara

\section{Research Article}

Keywords: Hydrothermal, Nickel cobalt oxide, Supercapacitor, Nonenzymatic glucose sensing

Posted Date: November 23rd, 2021

DOI: https://doi.org/10.21203/rs.3.rs-1098022/v1

License: (a) (i) This work is licensed under a Creative Commons Attribution 4.0 International License.

Read Full License 


\section{Abstract}

Herein, various nickel cobalt oxide nanostructures with different Ni concentrations are prepared via hydrothermal route and then calcination process for electrochemical supercapacitor as well as nonenzymatic glucose biosensor. The electrode synthesized on carbon cloth using $\mathrm{Ni}_{0.9} \mathrm{Co}_{2.1} \mathrm{O}_{4}$ nanosheet-like morphology showed a maximum $516.51 \mathrm{~F} \mathrm{~g}^{-1}$ specific capacitance at $10 \mathrm{mV} \mathrm{s}^{-1}$ scan rate and the cyclic stability of $87.7 \%$ over $2000 \mathrm{GCD}$ cycles. The electrode prepared with $\mathrm{Ni}_{0.3} \mathrm{Co}_{2.7} \mathrm{O}_{4}$ on $\mathrm{CC}$ offered a linear response from 0 to $0.3 \mathrm{mM}$ glucose concentration and exhibited a maximum of 759.5 $\mu \mathrm{A} \mathrm{mM} \mathrm{m}^{-1} \mathrm{~cm}^{-2}$ glucose sensitivity.

\section{Introduction}

Nowadays, human beings have suffered from problems such as deficiency of fossil fuels, global warming, and pollution. Hence, it is essential to produce energy from renewable sources Like solar, tide, and wind. Also, low-cost, environmentally friendly, advanced energy storage and conversion devices must store energy harvested from renewable resources ${ }^{1-4}$. There are different energy storage devices such as conventional capacitors, biofuel, lithium ions batteries (LIBs), and supercapacitors ${ }^{5-9}$. Supercapacitors, also called electrochemical supercapacitors, are the most desirable candidates for energy storage. Their unique electrochemical properties like high power density, excellent coulombic efficiency, and high cyclic stability make them compatible with other energy storage devices. Still, supercapacitors suffered from low energy density as compared to LIBs. So, to improve the energy density of supercapacitors, efforts have been made to develop novel electrodes with suitable synthesis strategies ${ }^{10-14}$.

The different conducting polymers ${ }^{15}$, transition metal oxides, and transition metal hydroxides such as $\mathrm{Co}_{3} \mathrm{O}_{4}{ }^{11}, \mathrm{NiO}{ }^{16}, \mathrm{Co}(\mathrm{OH})_{2}{ }^{17}, \mathrm{Ni}(\mathrm{OH})_{2}{ }^{18}, \mathrm{RuO}_{2}{ }^{19}, \mathrm{MnO}_{2}{ }^{20}$ has been widely studied as an electrode for pseudocapacitors. The transition metal oxides deliver higher specific capacitance as compared to conducting polymers due to multi-electron redox reactions. In addition, ternary metal oxides, because of their better electrical conductivity and rich redox-active sites, shows better supercapacitor performance than single metal oxide ${ }^{21}$. Spinel nickel cobalt oxide (NiCo204) has been widely used as high-performance capacitive electrode material in recent years. It shows better electrical conductivity, relatively lower electron transport activation energy, and better electrochemical activity than cobalt oxide $\left(\mathrm{CO}_{3} \mathrm{O}_{4}\right)$ and nickel oxide $(\mathrm{NiO}){ }^{22,23}$. This high electrical conductivity and improved specific capacitance of $\mathrm{NiCO}_{2} \mathrm{O}_{4}$ are because of contributions from both the $\mathrm{Co}$ and $\mathrm{Ni}$ ions with diverse valence states.

Researchers have made many efforts to enhance electrochemical performance by developing nickel cobalt oxide with different morphologies. Waghmode et al. ${ }^{24}$ synthesized $\mathrm{NiCO}_{2} \mathrm{O}_{4}$ nanoflowers by chemical bath deposition method and observed capacitance was $610 \mathrm{~F} \mathrm{~g}^{-1}$ at $1 \mathrm{~mA} \mathrm{~cm}{ }^{-2}$. Ma et al. ${ }^{25}$, with the solution precursor thermal spray method, developed $\mathrm{NiCO}_{2} \mathrm{O}_{4}$ hollow microspheres, which showed specific capacitance $902 \mathrm{~F} \mathrm{~g}^{-1}$ at $1 \mathrm{~A} \mathrm{~g}^{-1}$. Qi et al. ${ }^{26}$ synthesized $\mathrm{NiCO}_{2} \mathrm{O}_{4}$ hollow microspheres by a 
hydrothermal method which showed specific capacitance $720 \mathrm{~F} \mathrm{~g}^{-1}$ at $2 \mathrm{~A} \mathrm{~g}^{-1}$. Saravanakumar et al. ${ }^{27}$ synthesized $\mathrm{NiCO}_{2} \mathrm{O}_{4}$ nanoparticles via hydrothermal route and observed specific capacitance was $294 \mathrm{~F}$ $\mathrm{g}^{-1}$ at $1 \mathrm{~A} \mathrm{~g}^{-1}$. Uke et al. ${ }^{28}$ synthesized $\mathrm{NiCO}_{2} \mathrm{O}_{4}$ nanomorphs by hydrothermal method and observed specific capacitance was $479 \mathrm{~F} \mathrm{~g}^{-1}$ with better retention.

In the medical industries, quality control in food and clinical diagnosis of diabetes; rapid, accurate, and sensitive detection of glucose is essential ${ }^{29,30}$. Recently, sensitive and selective enzyme-based sensors have been studied for glucose sensing. But, they cannot be reused for continuous glucose detection. They suffer from low stability, which limits their use in actual application ${ }^{31,32}$. The other method, i.e., nonenzymatic glucose biosensing, exhibited high stability, sensitivity, and reproducibility. Qin et al. ${ }^{33}$ developed $\mathrm{NiCO}_{2} \mathrm{O}_{4}$ nanowires with the help of hydrothermal and calcination treatment. The prepared glucose sensor shows $72.4 \mathrm{mM} \mathrm{mM}^{-1} \mathrm{~cm}^{-2}$ glucose sensitivity and $0.37 \mathrm{mM}$ detection limit. Hussain et al. ${ }^{34}$ prepared $\mathrm{NiCO}_{2} \mathrm{O}_{4}$ nanoneedles on Nickel Foam exhibited a sensitivity of 91.34 $\mathrm{mV} /$ decade with a response time less than $10 \mathrm{~s}$. Yang et al. ${ }^{35}$ synthesized hollow nanorods of $\mathrm{NiCO}_{2} \mathrm{O}_{4}$ with the help of sacrificial template accelerate hydrolysis method achieved $1685.1 \mathrm{mM} \mathrm{mM}^{-1} \mathrm{~cm}^{-2} \mathrm{glucose}$ sensitivity. Ma et al. ${ }^{36}$ developed $\mathrm{NiCO}_{2} \mathrm{O}_{4}$ nanowrinkles on graphene oxide sheets with hydrothermal route achieved glucose sensitivity of $548.9 \mathrm{mM} \mathrm{mM}^{-1} \mathrm{~cm}^{-2}$.

In the present investigation, the different nickel cobalt oxide nanostructures by varying concentrations of $\mathrm{Ni}$ in cobalt oxide are prepared by the hydrothermal route and studied for both supercapacitor and glucose biosensing applications. The electrodes are synthesized using a flexible carbon cloth (CC) current collector with a simple doctor blade method. The synthesized $\mathrm{Ni}_{0.9} \mathrm{Co}_{2.1} \mathrm{O}_{4}$ nanosheets exhibited $516.51 \mathrm{~F}$ $\mathrm{g}^{-1}$ specific capacitance at $10 \mathrm{mV} \mathrm{s}^{-1}$ with capacity retention of $87.7 \%$ over 2000 cycles. At the same time, $\mathrm{Ni}_{0.3} \mathrm{Co}_{2.7} \mathrm{O}_{4}$ nanosheets showed maximum $759.5 \mu \mathrm{A} \mathrm{mM}^{-1} \mathrm{~cm}^{-2}$ glucose sensitivity with ${ }^{\text {a linear response }}$ from 0.0 to $0.3 \mathrm{mM}$ glucose concentration.

\section{Experimental}

\section{A. Preparation of different Nickel cobalt oxide powders:}

The nickel cobalt oxide powders with different Ni percentages were synthesized by the hydrothermal route and then calcination. In a synthesis of $\mathrm{Co}_{3} \mathrm{O}_{4}, 0.1 \mathrm{M} \mathrm{Co}\left(\mathrm{NO}_{3}\right)_{2} 6 \mathrm{H}_{2} \mathrm{O}$ and $0.2 \mathrm{M}$ of urea were added in Double distilled water (DDW). $\mathrm{NH}_{3}$ was added to the solution dropwise up to $\mathrm{pH}=11$ and stirred for 30 min. Afterward, the whole solution was poured into a Teflon liner $(100 \mathrm{~mL})$, fitted in stainless-steel autoclave and reaction carried out at $180^{\circ} \mathrm{C}$ for $18 \mathrm{~h}$. Then, the autoclave was cooled to room temperature, and reaction products were cleaned with DDW and ethanol many times and dried at $60^{\circ} \mathrm{C}$ oven for $12 \mathrm{~h}$. Lastly, the prepared powder was calcinated at $400^{\circ} \mathrm{C}$ for $2 \mathrm{~h}$. Similarly, powders with different $\mathrm{Ni}$ concentrations were synthesized by adding a different percentage of $\mathrm{Ni}$ as $0 \%, 10 \%, 20 \%$, 
$30 \%$, and $40 \%$ in $\mathrm{Co}_{3} \mathrm{O}_{4}$. Based on the various percentages of Ni precursor, the stoichiometries are observed $\mathrm{Co}_{3} \mathrm{O}_{4}, \mathrm{Ni}_{0.3} \mathrm{Co}_{2.7} \mathrm{O}_{4}, \mathrm{Ni}_{0.6} \mathrm{Co}_{2.4} \mathrm{O}_{4}, \mathrm{Ni}_{0.9} \mathrm{Co}_{2.1} \mathrm{O}_{4}$, and $\mathrm{Ni}_{1.2} \mathrm{Co}_{1.8} \mathrm{O}_{4}$, respectively.

\section{B. Preparation of electrode}

In an ultrasonication bath, a piece of $\mathrm{CC}\left(2 \mathrm{~cm}{ }^{\prime} 1 \mathrm{~cm}\right)$ was cleaned with ethanol, acetone, and DDW each for $10 \mathrm{~min}$ respectively, and dried overnight at $60^{\circ} \mathrm{C}$ in the oven. The actual electrode was prepared by mixing prepared powders (active material), PVDF as a binder, and a carbon black ratio of 80:10:10. Then sufficient amount of NMP solvent was mixed to obtain a uniform slurry. Then the prepared slurry was coated on CC $(1 \mathrm{~cm} 1 \mathrm{~cm})$ and subjected to $80^{\circ} \mathrm{C}$ in a hot air oven for $12 \mathrm{~h}$. These prepared electrodes were used for electrochemical supercapacitor and nonenzymatic glucose biosensor study. The experimental procedure can be presented in Fig. 1.

XRD pattern of prepared powders recorded using a Bruker D2 phaser tabletop model under Cu Ka radiation. FTIR was taken by Lambada-7600, Australia. The morphology was analyzed using FE-SEM from the Mira-3, Tescan, Brno-Czech Republic. Biologic SP-300 electrochemical workstation used for electrochemical supercapacitor and glucose biosensor study.

\section{Results And Discussion}

\subsection{XRD study}

Fig. 2 (A) presents the XRD spectra of different Nickel cobalt oxide nanostructures. The observed dspacing values in XRD spectra are associated with standard JCPDS card 01-080-1543 for $\mathrm{Co}_{3} \mathrm{O}_{4}$ and 01073-1702 after adding different $\mathrm{Ni}$ concentrations. The peaks are observed at an angle, 64.98, 59.19, $44.68,36.79,31.16,18.94^{\circ}$ which applied to the cubic structure and assigned to the (440), (511), (400), (311), (220), and (111) crystal planes respectively. The crystallite size is calculated by using Scherer's formula 7,37 . The calculated values for average crystallite size are $34.18,36.61,43.10,30.96$, and 34.18 $\mathrm{nm}$ for $\mathrm{Co}_{3} \mathrm{O}_{4}, \mathrm{Ni}_{0.3} \mathrm{Co}_{2.7} \mathrm{O}_{4}, \mathrm{Ni}_{0.6} \mathrm{Co}_{2.4} \mathrm{O}_{4}, \mathrm{Ni}_{0.9} \mathrm{Co}_{2.1} \mathrm{O}_{4}$, and $\mathrm{Ni}_{1.2} \mathrm{Co}_{1.8} \mathrm{O}_{4}$, respectively.

\subsection{FTIR study}

The different Nickel cobalt oxide powders were further characterized by the FT-IR study. Fig. 2 (B) presents the FTIR spectra of all synthesized nickel cobalt oxide powders. The FTIR spectra display two sharp peaks at about $661 \mathrm{~cm}^{-1}$ and $565 \mathrm{~cm}^{-1}$ which are originated from Co-O bonds (stretching vibrations), confirms the formation of $\mathrm{CO}_{3} \mathrm{O}_{4}{ }^{38,39}$. As the percentage of $\mathrm{Ni}$ increases, these two peaks shift towards a higher wavenumber. The corresponding change in the peak is mentioned in supplementary information Table S1. The relatively weak peaks at about 1632 and $3432 \mathrm{~cm}^{-1}$ are associated with $\mathrm{O}-\mathrm{H}$ bending and stretching mode of vibration of water ${ }^{40-42}$. 


\subsection{FE-SEM study}

Fig. 3 shows FE-SEM pictures and EDS analysis of different nickel cobalt oxide powders. The $\mathrm{Co}_{3} \mathrm{O}_{4}$ in Fig. $3(\mathrm{~A})$ shows nanosheets like nature. As the different percentages of $\mathrm{Ni}$ are added into $\mathrm{Co}_{3} \mathrm{O}_{4}$, surface modifications are observed. In Fig. $3(\mathrm{~B})$, the nanosheet-like morphologies are observed, which are merged. As the percentage of $\mathrm{Ni}$ increases, the nanosheets are incorporated a lot in Fig. 3 (C). The flakes are started covered with nanoparticles in Fig. 3 (D), and finally, the number of nanoparticles increased as shown in Fig. $3 €$ corresponding to the $\mathrm{Ni}_{1.2} \mathrm{Co}_{1.8} \mathrm{O}_{4}$. Fig. $3(\mathrm{~F})$ shows the EDS spectra of $\mathrm{Ni}_{1.2} \mathrm{Co}_{1.8} \mathrm{O}_{4}$, which confirms the presence of $\mathrm{Ni}, \mathrm{Co}$, and $\mathrm{O}$. Fig. 3 (G-I) presets the elemental distribution of $\mathrm{Ni}, \mathrm{Co}$, and $\mathrm{O}$, respectively.

\subsection{ElS study}

The electrochemical behavior at the electrode-electrolyte interface was studied by using the EIS study. Fig. 4 presents the EIS study of synthesized $\mathrm{Co}_{3} \mathrm{O}_{4}, \mathrm{Ni}_{0.3} \mathrm{Co}_{2.7} \mathrm{O}_{4}, \mathrm{Ni}_{0.6} \mathrm{Co}_{2.4} \mathrm{O}_{4}, \mathrm{Ni}_{0.9} \mathrm{Co}_{2.1} \mathrm{O}_{4}$, and $\mathrm{Ni}_{1.2} \mathrm{Co}_{1.8} \mathrm{O}_{4}$ electrodes. ElS spectra were recorded within $1 \mathrm{MHz}$ to $0.1 \mathrm{~Hz}$ frequency range in $1 \mathrm{M} \mathrm{KOH}$ electrolyte at applied potential $20 \mathrm{mV}$. Fig. 4 (A) presents the Nyquist plots of $\mathrm{Co}_{3} \mathrm{O}_{4}, \mathrm{Ni}_{0.3} \mathrm{Co}_{2.7} \mathrm{O}_{4}$, $\mathrm{Ni}_{0.6} \mathrm{Co}_{2.4} \mathrm{O}_{4}, \mathrm{Ni}_{0.9} \mathrm{Co}_{2.1} \mathrm{O}_{4}$, and $\mathrm{Ni}_{1.2} \mathrm{Co}_{1.8} \mathrm{O}_{4}$ electrodes. The Inset of Fig. 4 (A) shows the corresponding fitted circuit diagram. The solution resistance $\left(R_{s}\right)$ values estimated from Nyquist plot for $\mathrm{Co}_{3} \mathrm{O}_{4}$, $\mathrm{Ni}_{0.3} \mathrm{Co}_{2.7} \mathrm{O}_{4}, \mathrm{Ni}_{0.6} \mathrm{Co}_{2.4} \mathrm{O}_{4}, \mathrm{Ni}_{0.9} \mathrm{Co}_{2.1} \mathrm{O}_{4}$, and $\mathrm{Ni}_{1.2} \mathrm{Co}_{1.8} \mathrm{O}_{4}$ electrodes are $0.08,0.37,0.36,0.02$, and $0.15 \mathrm{~W} \mathrm{~cm}^{-2}$. The charge transfer resistance values for $\mathrm{Co}_{3} \mathrm{O}_{4}, \mathrm{Ni}_{0.3} \mathrm{Co}_{2.7} \mathrm{O}_{4}, \mathrm{Ni}_{0.6} \mathrm{Co}_{2.4} \mathrm{O}_{4}, \mathrm{Ni}_{0.9} \mathrm{Co}_{2.1} \mathrm{O}_{4}$, and $\mathrm{Ni}_{1.2} \mathrm{Co}_{1.8} \mathrm{O}_{4}$ electrodes are 88.81, 91.51, 109.10, 79.51, and $90.47 \mathrm{~W} \mathrm{~cm}^{-2}$ respectively. The lower $\mathrm{R}_{\mathrm{ct}}$ and $R_{S}$ values reveal the better electrical conductivity and good adhesion of coated material with current collector ${ }^{43}$. The different EIS parameters are mentioned in supplementary information Table S2. Fig. 4 (B) presents the Bode plot of $\mathrm{Co}_{3} \mathrm{O}_{4}, \mathrm{Ni}_{0.3} \mathrm{Co}_{2.7} \mathrm{O}_{4}, \mathrm{Ni}_{0.6} \mathrm{Co}_{2.4} \mathrm{O}_{4}, \mathrm{Ni}_{0.9} \mathrm{Co}_{2.1} \mathrm{O}_{4}$, and $\mathrm{Ni}_{1.2} \mathrm{Co}_{1.8} \mathrm{O}_{4}$ electrodes, respectively.

\subsection{Electrochemical supercapacitor study}

The three-electrode system with SCE as a reference electrode, platinum wire counter electrode, and prepared CC electrodes as a working electrode is used to study electrochemical supercapacitor performance. The electrochemical performance is studied in $1 \mathrm{M} \mathrm{KOH}$ electrolyte.

Fig. $5 \mathrm{~A}$ presents the cyclic voltammetry (CV) curves of all nickel cobalt oxide electrodes studied at a 10 $\mathrm{mV} \mathrm{s}^{-1}$ scan rate The maximum capacitance values estimated from CV curves are 189.31, 204.22, 
220.63, 516.51, and $312.32 \mathrm{~F} \mathrm{~g}^{-1}$ for $\mathrm{Co}_{3} \mathrm{O}_{4}, \mathrm{Ni}_{0.3} \mathrm{Co}_{2.7} \mathrm{O}_{4}, \mathrm{Ni}_{0.6} \mathrm{Co}_{2.4} \mathrm{O}_{4}, \mathrm{Ni}_{0.9} \mathrm{Co}_{2.1} \mathrm{O}_{4}$, and $\mathrm{Ni}_{1.2} \mathrm{Co}_{1.8} \mathrm{O}_{4}$ electrodes, respectively. All CVs, along with different scan rates, are mentioned in Fig. S1 (A-E). From the graphs in Fig. S1, it is clear that with an increase in scan rate, the area under the curve increases as the current drawn increases with the voltage in the CV graph. But the increase in scan rate limits the interaction time between electrolyte and electrode. This limited-time interaction between electrode and electrolyte also limits the utilization of the active surface area of the electrode. Hence specific capacitance decreases with the increase of scan rate ${ }^{44}$.

The galvanostatic charge-discharge curves are displayed in fig. $5 \mathrm{~B}$ of different nickel cobalt oxide electrodes studied at current density $3 \mathrm{~mA} \mathrm{~cm}^{-2}$. The maximum specific capacitance values estimated from GCD curves are 89.10, 101.27, 165.38, 455.27, and $337.01 \mathrm{~F} \mathrm{~g}^{-1}$ for $\mathrm{Co}_{3} \mathrm{O}_{4}, \mathrm{Ni}_{0.3} \mathrm{Co}_{2.7} \mathrm{O}_{4}$, $\mathrm{Ni}_{0.6} \mathrm{Co}_{2.4} \mathrm{O}_{4}, \mathrm{Ni}_{0.9} \mathrm{Co}_{2.1} \mathrm{O}_{4}$, and $\mathrm{Ni}_{1.2} \mathrm{Co}_{1.8} \mathrm{O}_{4}$ electrodes, respectively. All GCD study with various current densities is mentioned in Fig. S2 (A-E). The cyclic stability is measured for the $\mathrm{Ni}_{0.9} \mathrm{Co}_{2.1} \mathrm{O}_{4}$ electrode as it exhibited a higher capacitance value than other nickel cobalt oxide nanostructured electrodes. The observed stability for the $\mathrm{Ni}_{0.9} \mathrm{Co}_{2.1} \mathrm{O}_{4}$ electrode is $87.7 \%$ over the 2000 charging-discharging cycles as depicted in Fig. $5 \mathrm{C}$. Inset image of Fig. $5 \mathrm{C}$ shows the first and last charging and discharging cycles. The higher specific capacitance and stability of $\mathrm{Ni}_{0.9} \mathrm{Co}_{2.1} \mathrm{O}_{4}$ electrode may be due to micro sheets covered nanospheres like morphology. The micro sheets and nanosphere morphology provide maximum surface area so that the interaction between electrode and electrolyte becomes easier, enhancing the specific capacitance value. The calculated specific capacitance from CV vs. scan rate is mentioned in fig. $5 \mathrm{D}$. In contrast, the variation of specific capacitance vs. current density is mentioned in fig. 5 E. Fig. $5 \mathrm{~F}$ presents the Regone plot. The maximum energy density for the $\mathrm{Ni}_{0.9} \mathrm{Co}_{2.1} \mathrm{O}_{4}$ electrode is $15.81 \mathrm{Wh} \mathrm{kg}^{-1}$ (at $0.75 \mathrm{~kW} \mathrm{~kg}^{-1}$ power density). The comparison of supercapacitor performance of present work and previously reported work is mentioned in Table. 1.

\subsection{Nonenzymatic glucose biosensing study}

Here the same three-electrode system is used for the glucose sensing study except for $0.1 \mathrm{M} \mathrm{NaOH}$ electrolyte. Fig. 6 (A-E) presents the CVs of $\mathrm{Co}_{3} \mathrm{O}_{4}, \mathrm{Ni}_{0.3} \mathrm{Co}_{2.7} \mathrm{O}_{4}, \mathrm{Ni}_{0.6} \mathrm{Co}_{2.4} \mathrm{O}_{4}, \mathrm{Ni}_{0.9} \mathrm{Co}_{2.1} \mathrm{O}_{4}$, and $\mathrm{Ni}_{1.2} \mathrm{Co}_{1.8} \mathrm{O}_{4}$ electrodes in the absence of glucose (red) and in the presence of $1.0 \mathrm{M}$ glucose (blue). Fig. 7 (A-E) presents the $\mathrm{CV}$ curves of $\mathrm{Co}_{3} \mathrm{O}_{4}, \mathrm{Ni}_{0.3} \mathrm{Co}_{2.7} \mathrm{O}_{4}, \mathrm{Ni}_{0.6} \mathrm{Co}_{2.4} \mathrm{O}_{4}, \mathrm{Ni}_{0.9} \mathrm{Co}_{2.1} \mathrm{O}_{4}$, and $\mathrm{Ni}_{1.2} \mathrm{Co}_{1.8} \mathrm{O}_{4}$ electrodes at different concentration of glucose $(0.0,0.2,0.4,0.6,0.8,1.0 \mathrm{M})$. Here we can observe that for all samples, peak currents are increased after the addition of glucose. The increase in the peak currents is explained as follows ${ }^{45}$, 


$$
\begin{aligned}
\mathrm{NiCo}_{2} \mathrm{O}_{4}+\mathrm{H}_{2} \mathrm{O}+\mathrm{OH}^{-} & \leftrightarrow \mathrm{NiOOH}+2 \mathrm{CoOOH}+\mathrm{e}^{-} \\
\mathrm{CoOOH}+\mathrm{OH}^{-} & \leftrightarrow \mathrm{CoO}_{2}+\mathrm{H}_{2} \mathrm{O}+\mathrm{e}^{-} \\
\mathrm{Ni}^{2+}+\mathrm{Co}^{2+} & \rightarrow \mathrm{Ni}^{3+}+\mathrm{Co}^{3+}+2 \mathrm{e}^{-}
\end{aligned}
$$

Glucose $\left(\mathrm{C}_{6} \mathrm{H}_{12} \mathrm{O}_{6}\right) \rightarrow$ Glucanolactone $\left(\mathrm{C}_{6} \mathrm{H}_{10} \mathrm{O}_{6}\right)+2 \mathrm{H}^{+}+2 \mathrm{e}^{-}$

During the oxidation, $\mathrm{Ni}^{2+}$ and $\mathrm{Co}^{2+}$ ions present in the $\mathrm{NiOOH}$ and $\mathrm{CoOOH}$ compounds oxidize to $\mathrm{Ni}^{3+}$ and $\mathrm{Co}^{3+}$ with the release of two electrons (eq. 1-3). After adding glucose, the glucose molecules dissociate and are converted into gluconolactone with the release of two electrons (eq. 4). During reduction, the oxidized species $\mathrm{Ni}^{3+}$ and $\mathrm{Co}^{3+}$ reduce back to the $\mathrm{Ni}^{2+}$ and $\mathrm{Co}^{2+}$ by accepting electrons and returning to their original states. Fig. 8 (A-E) presents the CV of different nickel cobalt oxide electrodes in the presence of $1.0 \mathrm{M}$ glucose at various scan rates $\left(10-100 \mathrm{mV} \mathrm{s}^{-1}\right)$. It can be seen that with scan rate, the anodic and cathodic peaks also increase. Fig. 9 (A-E) presents the chronoamperometry study (I vs. t) of each nickel cobalt oxide electrode at $0.4 \mathrm{~V}$ applied potential with the subsequent addition of $0.05 \mathrm{mM}$ glucose into $0.1 \mathrm{M} \mathrm{NaOH}$ electrolyte. The inset of Fig. 9 (A-E) shows their calibration curves of Amperometric responses. The observed sensitivities for $\mathrm{Co}_{3} \mathrm{O}_{4}, \mathrm{Ni}_{0.3} \mathrm{Co}_{2.7} \mathrm{O}_{4}, \mathrm{Ni}_{0.6} \mathrm{Co}_{2.4} \mathrm{O}_{4}, \mathrm{Ni}_{0.9} \mathrm{Co}_{2.1} \mathrm{O}_{4}$, and $\mathrm{Ni}_{1.2} \mathrm{Co}_{1.8} \mathrm{O}_{4}$ electrodes are $370.7,759.5,747.4,557.7,688.1 \mu \mathrm{AmM}^{-1} \mathrm{~cm}^{-2}$, respectively. The Nyquist plots in the absence of glucose and in the presence of $1.0 \mathrm{mM}$ glucose are shown in supplementary information Fig. S3. The estimated glucose-sensing parameters are given in Table 2. As shown in Fig. 10 (A-E), the selectivity of samples was examined by addition $0.2 \mathrm{mM}$ glucose and other interfering species [0.0125 mM of uric acid (UA), Ascorbic acid (AA), Fructose (FR), Sucrose (SA), and Lactic acid (LA)]. All the electrodes showed a negligible effect of interfering species as compared to glucose. The response times for all prepared electrodes are mentioned in Fig. S4 (Supplementary data). The comparative glucose-sensing study of current work and previously reported work is mentioned in Table. 3.

\section{Conclusion}

In summary, the nickel cobalt oxide by varying $\mathrm{Ni}$ concentrations has been prepared by the hydrothermal method. The nanosheet like $\mathrm{Ni}_{0.9} \mathrm{Co}_{2.1} \mathrm{O}_{4}$ electrode exhibited $516.51 \mathrm{~F} \mathrm{~g}^{-1}$ specific capacitance at $10 \mathrm{mV}$ $\mathrm{s}^{-1}$ and cyclic stability of $87.7 \%$ over 2000 galvanostatic charge-discharge cycles. Also, it showed an energy density of $15.81 \mathrm{Wh} \mathrm{kg}^{-1}$ at $0.75 \mathrm{~kW} \mathrm{~kg}^{-1}$ power density. The $\mathrm{Ni}_{0.3} \mathrm{Co}_{2.7} \mathrm{O}_{4}$ nanosheets on $\mathrm{CC}$ showed linear response from 0 to $0.3 \mathrm{mM}$ glucose concentration and exhibited the highest glucose sensitivity of $759.5 \mu \mathrm{AmM}^{-1} \mathrm{~cm}^{-2}$. The overall study is a platform for the development of a flexible, high stability supercapacitor and reliable nonenzymatic glucose sensor.

\section{Declarations}




\section{Acknowledgment}

Authors thankful to DST-SERB government of India for providing financial support under, Early career research award Scheme File no. ECR/2017/002099.

\section{References}

1. Hwang, J. Y., Myung, S. T. \& Sun, Y. K. Sodium-ion batteries: Present and future. Chem. Soc. Rev, 46, 3529-3614 (2017).

2. Lokhande, V. C., Lokhande, A. C., Lokhande, C. D., Kim, J. H. \& Ji, T. Supercapacitive composite metal oxide electrodes formed with carbon, metal oxides and conducting polymers. Journal of Alloys and Compounds, 682, 381-403 (2016).

3. Yan, J., Wang, Q., Wei, T. \& Fan, Z. Recent Advances in Design and Fabrication of Electrochemical Supercapacitors with High Energy Densities. Adv. Energy Mater, 4, 1300816 (2014).

4. Adhikari, H. et al. Template-free synthesis of hierarchical mixed-metal cobaltites: Electrocapacitive and Theoretical study. Electrochim. Acta, 225, 514-524 (2017).

5. Pan, X. et al. High-performance supercapacitors based on superior $\mathrm{Co304}$ nanorods electrode for integrated energy harvesting-storage system. Electrochim. Acta, 282, 905-912 (2018).

6. Low, W. H., Khiew, P. S., Lim, S. S., Siong, C. W. \& Ezeigwe, E. R. Recent development of mixed transition metal oxide and graphene/mixed transition metal oxide based hybrid nanostructures for advanced supercapacitors. Journal of Alloys and Compounds, 775, 1324-1356 (2019).

7. Lohar, G. M., Dhaygude, H. D., Relekar, B. P., Rath, M. C. \& Fulari, V. J. Effect of $10 \mathrm{MeV}$ energy of electron irradiation on Fe2+ doped ZnSe nanorods and their modified properties. Ionics (Kiel), 22, 1451-1460 (2016).

8. Relekar, B. P., Fulari, A. V., Lohar, G. M. \& Fulari, V. J. Development of Porous Manganese Oxide/Polyaniline Composite Using Electrochemical Route for Electrochemical Supercapacitor. J. Electron. Mater, 48, 2449-2455 (2019).

9. Relekar, B. P., Fulari, A. V., Rath, M. C., Fulari, V. J. \& Lohar, G. M. Modification in porous MnO2/PANI composite using high-energy electron irradiation for electrochemical supercapacitor. J. Mater. Sci. Mater. Electron, 31, 11741-11747 (2020).

10. Liu, C., Jiang, W., Hu, F., Wu, X. \& Xue, D. Mesoporous NiCo2O4 nanoneedle arrays as supercapacitor electrode materials with excellent cycling stabilities. Inorg. Chem. Front, 5, 835-843 (2018).

11. Wang, X. et al. Embedded Ag quantum dots into interconnected Co304 nanosheets grown on 3D graphene networks for high stable and flexible supercapacitors. Electrochim. Acta, 224, 260-268 (2017).

12. Yan, Y., Li, B., Guo, W., Pang, H. \& Xue, H. Vanadium based materials as electrode materials for high performance supercapacitors. Journal of Power Sources, 329, 148-169 (2016). 
13. Fulari, A. V. et al. TiO2/reduced graphene oxide composite based nano-petals for supercapacitor application: effect of substrate. J. Mater. Sci. Mater. Electron, 29, 10814-10824 (2018).

14. Relekar, B. P., Fulari, A. V., Rath, M. C., Fulari, V. J. \& Lohar, G. M. Modification in porous MnO2/PANI composite using high-energy electron irradiation for electrochemical supercapacitor. J. Mater. Sci. Mater. Electron, 31, 11741-11747 (2020).

15. Zhang, H. et al. Stable p/n-Dopable Conducting Redox Polymers for High-Voltage Pseudocapacitor Electrode Materials: Structure-Performance Relationship and Detailed Investigation into ChargeTrapping Effect. Adv. Energy Mater, 7, 1701063 (2017).

16. Guo, X. et al. Controllable synthesis of a NiO hierarchical microspheres/nanofibers composites assembled on nickel foam for supercapacitor. Mater. Lett, 240, 62-65 (2019).

17. Zhao, C. et al. A high-performance asymmetric supercapacitor based on $\mathrm{Co}(\mathrm{OH}) 2 /$ graphene and activated carbon electrodes. J. Electroanal. Chem, 782, 98-102 (2016).

18. Abitkar, S. B., Jadhav, P. R., Tarwal, N. L., Moholkar, A. V. \& Patil, C. E. A facile synthesis of a-Ni(OH)2CNT composite films for supercapacitor application. Adv. Powder Technol, 30, 2285-2292 (2019).

19. Thangappan, R., Arivanandhan, M., Dhinesh Kumar, R. \& Jayavel, R. Facile synthesis of RuO2 nanoparticles anchored on graphene nanosheets for high performance composite electrode for supercapacitor applications. J. Phys. Chem. Solids, 121, 339-349 (2018).

20. Wang, F. et al. Preparation of novel hollow $\delta-M n O 2$ composite sphere for supercapacitors and degradation of bisphenol A. Mater. Res. Bull, 115, 257-261 (2019).

21. Hao, C. et al. Preparation of Hierarchical Spinel NiCo204 Nanowires for High-Performance Supercapacitors. Ind. Eng. Chem. Res, 57, 2517-2525 (2018).

22. Du, H. et al. Boosting the capacitance of NiCo2O4 hierarchical structures on nickel foam in supercapacitors. Int. J. Hydrogen Energy, 43, 15348-15357 (2018).

23. Hao, C. et al. Preparation of hierarchical spinel NiCo2O4 nanowires for high-performance supercapacitors. Ind. Eng. Chem. Res, 57, 2517-2525 (2018).

24. Waghmode, R. B., Jadhav, H. S., Kanade, K. G. \& Torane, A. P. Morphology-controlled synthesis of NiCo2O4 nanoflowers on stainless steel substrates as high-performance supercapacitors. Mater. Sci. Energy Technol, 2, 556-564 (2019).

25. Ma, Y. et al. Deposition of binder-free oxygen-vacancies NiCo 204 based films with hollow microspheres via solution precursor thermal spray for supercapacitors. Ceram. Int, 45, 10722-10732 (2019).

26. Qi, X. et al. NiCo2O4 hollow microspheres with tunable numbers and thickness of shell for supercapacitors. Chem. Eng. J, 309, 426-434 (2017).

27. Saravanakumar, B. et al. Hydrothermal synthesis of spherical NiCO2O4 nanoparticles as a positive electrode for pseudocapacitor applications. J. Sol-Gel Sci. Technol, 84, 297-305 (2017).

28. Uke, S. J., Chaudhari, G. N., Bodade, A. B. \& Mardikar, S. P. Morphology dependant electrochemical performance of hydrothermally synthesized NiCo2O4 nanomorphs. Mater. Sci. Energy Technol, 3, 
289-298 (2020).

29. Wu, S. et al. An ultrasensitive electrochemical biosensing platform for fructose and xylitol based on boronic acid-diol recognition. Sensors Actuators, B Chem, 245, 11-17 (2017).

30. Zheng, W., Hu, L., Lee, L. Y. S. \& Wong, K. Y. Copper nanoparticles/polyaniline/graphene composite as a highly sensitive electrochemical glucose sensor. J. Electroanal. Chem, 781, 155-160 (2016).

31. Radhakrishnan, S. \& Kim, S. J. Facile fabrication of NiS and a reduced graphene oxide hybrid film for nonenzymatic detection of glucose. RSC Adv, 5, 44346-44352 (2015).

32. Suneesh, P. V., Chandhini, K., Ramachandran, T. \& Nair, B. G. Satheesh Babu, T. G. Tantalum oxide honeycomb architectures for the development of a non-enzymatic glucose sensor with wide detection range. Biosens. Bioelectron, 50, 472-477 (2013).

33. Qin, Z., Cheng, Q., Lu, Y. \& Li, J. Facile synthesis of hierarchically mesoporous NiCo204 nanowires for sensitive nonenzymatic glucose detection.Appl. Phys. A Mater. Sci. Process.123, (2017)

34. Hussain, M. et al. Synthesis of Three Dimensional Nickel Cobalt Oxide Nanoneedles on Nickel Foam, Their Characterization and Glucose Sensing Application. Sensors 2014, Vol. 14, 5415-5425 (2014).

35. Yang, J., Cho, M. \& Bioelectronics, Y. L. B. and \& 2016, undefined. Synthesis of hierarchical NiCo2O4 hollow nanorods via sacrificial-template accelerate hydrolysis for electrochemical glucose oxidation. Elsevier

36. Ma, G. et al. Preparation of spinel nickel-cobalt oxide nanowrinkles/reduced graphene oxide hybrid for nonenzymatic glucose detection at physiological level. Elsevier

37. Geng, J. et al. Energy band investigation and role of Fe content in Zn 1-x Fe x Se based nanomaterials for photoelectrochemical cell application. Ceram. Int, 45, 14457-14463 (2019).

38. Makhlouf, S. A., Bakr, Z. H., Aly, K. I. \& Moustafa, M. S. Structural, electrical and optical properties of Co30 4 nanoparticles. Superlattices Microstruct, 64, 107-117 (2013).

39. Prabaharan, D. D. M., Sadaiyandi, K., Mahendran, M. \& Sagadevan, S. Precipitation method and characterization of cobalt oxide nanoparticles. Appl. Phys. A Mater. Sci. Process, 123, 1-6 (2017).

40. Fulari, A. V. et al. TiO2/reduced graphene oxide composite based nano-petals for supercapacitor application: effect of substrate. J. Mater. Sci. Mater. Electron, 29, 10814-10824 (2018).

41. Liu, F. et al. Facile synthesis of ultrafine cobalt oxide nanoparticles for high-performance supercapacitors. J. Colloid Interface Sci, 505, 796-804 (2017).

42. Liu, S. et al. Optimized core-shell polypyrrole-coated NiCo2O4 nanowires as binder-free electrode for high-energy and durable aqueous asymmetric supercapacitor. J. Mater. Sci, 53, 2658-2668 (2018).

43. Liu, P., Yang, M., Zhou, S., Huang, Y. \& Zhu, Y. Hierarchical shell-core structures of concave spherical NiO nanospines@carbon for high performance supercapacitor electrodes. Electrochim. Acta, 294, 383-390 (2019).

44. Pore, O. C. et al. Hydrothermally synthesized urchinlike NiO nanostructures for supercapacitor and nonenzymatic glucose biosensing application. Mater. Sci. Semicond. Process, 134, 105980 (2021). 
45. Naik, K. K., Kumar, S. \& Rout, C. S. Electrodeposited spinel NiCo2O4 nanosheet arrays for glucose sensing application. RSC Adv, 5, 74585-74591 (2015).

46. Saravanakumar, B. et al. Hydrothermal synthesis of spherical NiCO2O4 nanoparticles as a positive electrode for pseudocapacitor applications. J. Sol-Gel Sci. Technol, 84, 297-305 (2017).

47. Maile, N. et al. Capacitive property studies of electrochemically synthesized Co3O4 and Mn304 on inexpensive stainless steel current collector for supercapacitor application. Ceram. Int, 46, 1464014649 (2020).

48. Wang, J. et al. Facile synthesis of three-dimensional NiCo2O4 with different morphology for supercapacitors. RSC Adv, 6, 70077-70084 (2016).

49. Xia, X. et al. Self-supported hydrothermal synthesized hollow Co304 nanowire arrays with high supercapacitor capacitance. J. Mater. Chem, 21, 9319-9325 (2011).

50. Tummala, R., Guduru, R. K. \& Mohanty, P. S. Nanostructured Co 304 electrodes for supercapacitor applications from plasma spray technique. J. Power Sources, 209, 44-51 (2012).

51. Tian, X. et al. Vertically/parallelly orientated growth of NiCo2O4 nanosheet onto surface of hierarchically N-doped porous carbon for improved supercapacitor. Mater. Technol, 35, 463-474 (2020).

52. Kim, T., Ramadoss, A., Saravanakumar, B., Veerasubramani, G. K. \& Kim, S. J. Synthesis and characterization of $\mathrm{NiCo} 2 \mathrm{O} 4$ nanoplates as efficient electrode materials for electrochemical supercapacitors. Appl. Surf. Sci, 370, 452-458 (2016).

53. Kuang, M., Zhang, W., Guo, X. L., Yu, L. \& Zhang, Y. X. Template-free and large-scale synthesis of hierarchical dandelion-like NiCo2O4 microspheres for high-performance supercapacitors. Ceram. Int, 40, 10005-10011 (2014).

54. Nguyen, N. V. et al. Facile Synthesis of a NiCo2O4 Nanoparticles Mesoporous Carbon Composite as Electrode Materials for Supercapacitor. ChemistrySelect, 5, 7060-7068 (2020).

55. Ding, Y. et al. Electrospun Co304 nanofibers for sensitive and selective glucose detection. Biosens. Bioelectron, 26, 542-548 (2010).

56. Cui, S. et al. Rectangular flake-like mesoporous NiCo2O4 as enzyme mimic for glucose biosensing and biofuel cell. Sci. China Mater, 60, 766-776 (2017).

57. Ma, G. et al. Preparation of spinel nickel-cobalt oxide nanowrinkles/reduced graphene oxide hybrid for nonenzymatic glucose detection at physiological level. Electrochim. Acta, 220, 545-553 (2016).

58. Jang, K. et al. Synthesis of NiCo2O4 Nanostructures and Their Electrochemial Properties for Glucose Detection. Nanomaterials, 11, 55 (2020).

59. Naik, K. K., Gangan, A., Chakraborty, B., Nayak, S. K. \& Rout, C. S. Enhanced Nonenzymatic GlucoseSensing Properties of Electrodeposited NiCo204-Pd Nanosheets: Experimental and DFT Investigations. ACS Appl. Mater. Interfaces, 9, 23894-23903 (2017).

\section{Tables}


Tables 1-3 are in the supplementary files section.

\section{Figures}

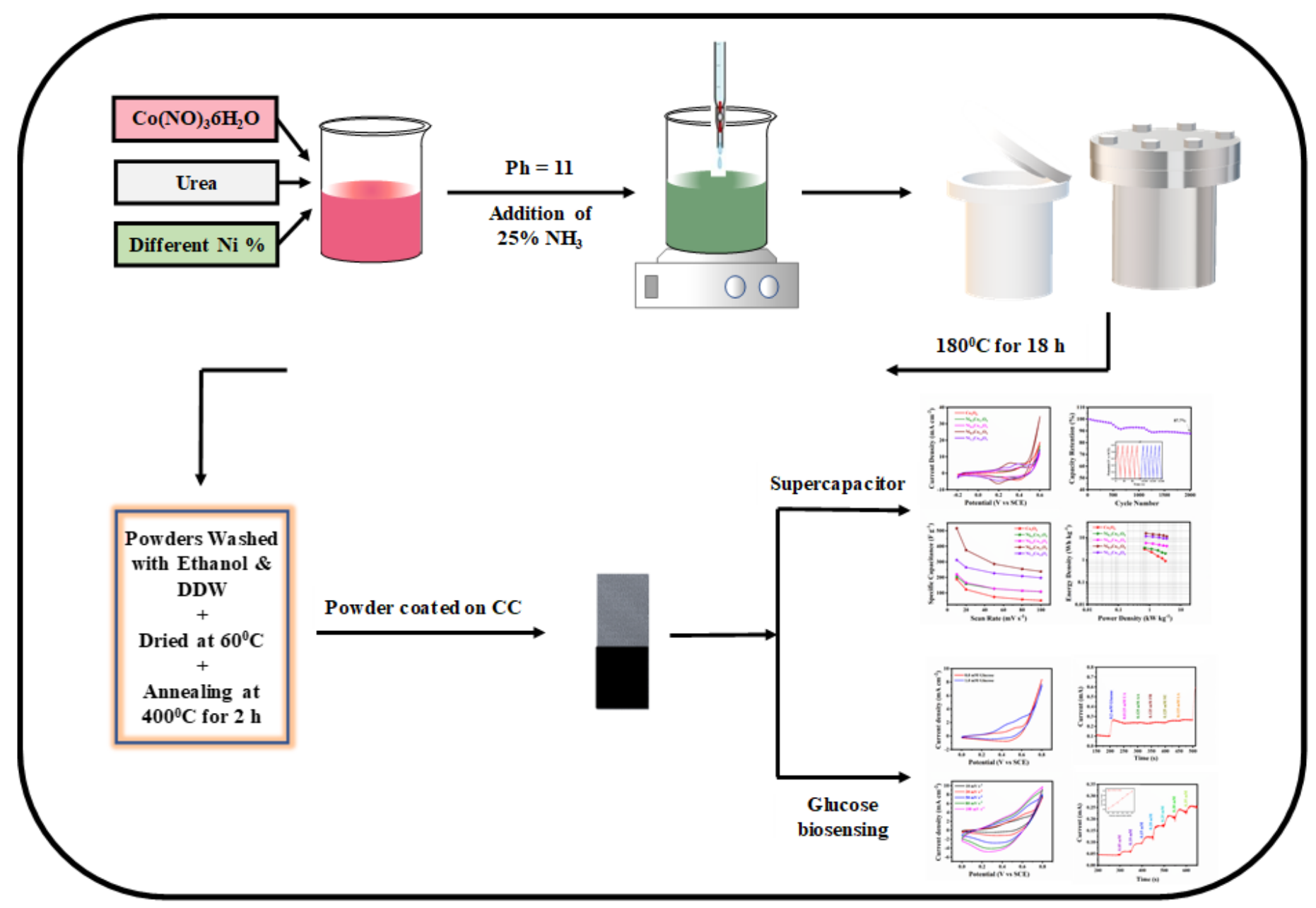

Figure 1

Schematic representation of overall experimental procedure. 

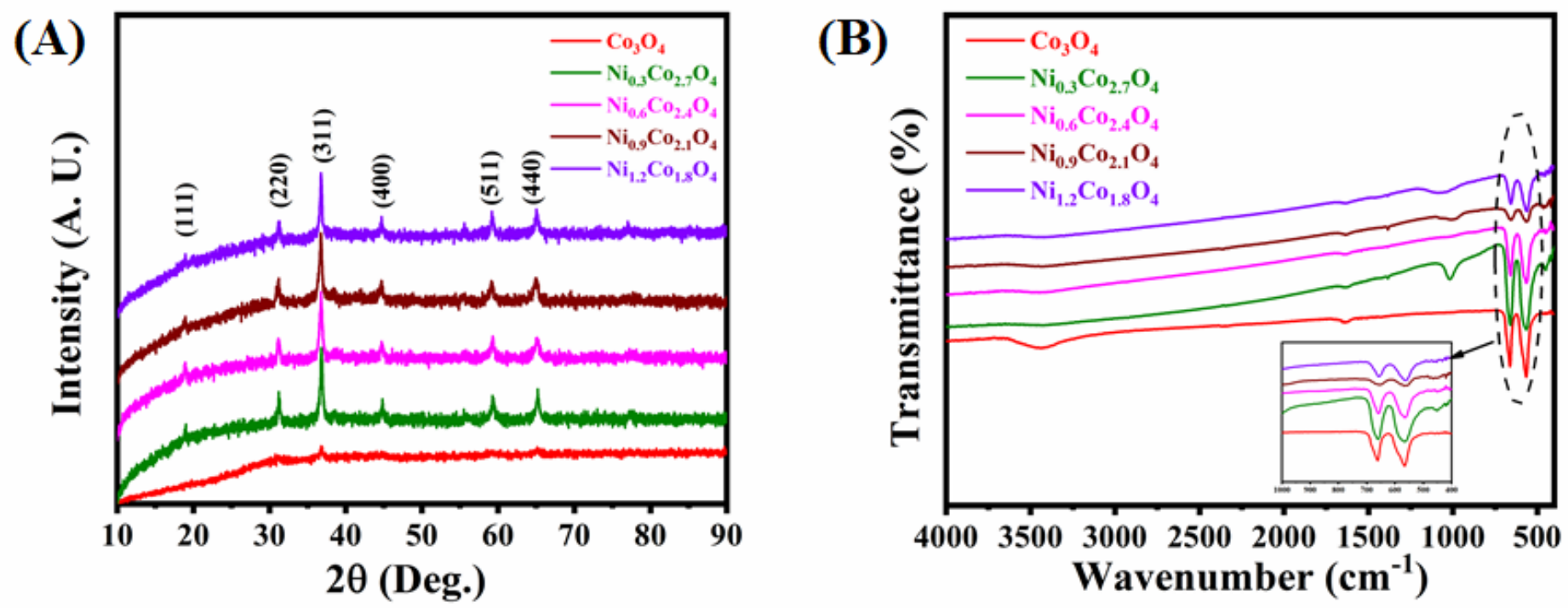

Figure 2

Structural analysis of nickel cobalt oxide (A) XRD spectra and (B) FTIR of nickel cobalt oxide powders with different Ni concentrations. 

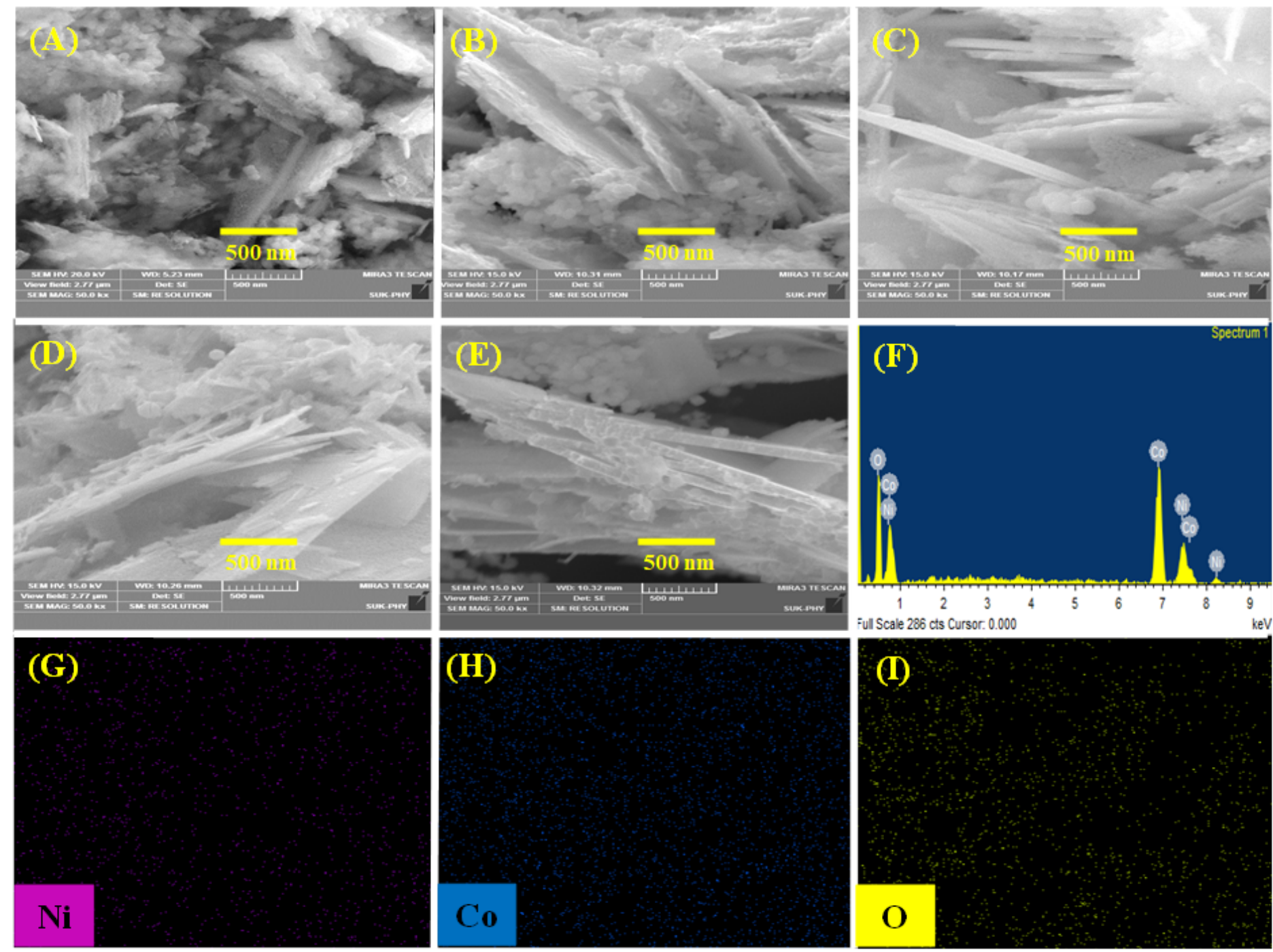

\section{Figure 3}

Morphology of nickel cobalt oxide powders. (A-E) FE-SEM images of Co304, Ni0.3Co2.704, $\mathrm{Ni0.6Co2.404,} \mathrm{Ni0.9Co2.104,} \mathrm{and} \mathrm{Ni1.2Co1.804} \mathrm{powders,} \mathrm{respectively.} \mathrm{(F)} \mathrm{EDS} \mathrm{image} \mathrm{of} \mathrm{Ni0.9Co2.104}$ powder. (G-I) Element distribution images of $\mathrm{Ni}, \mathrm{Co}$, and $\mathrm{O}$, respectively. 

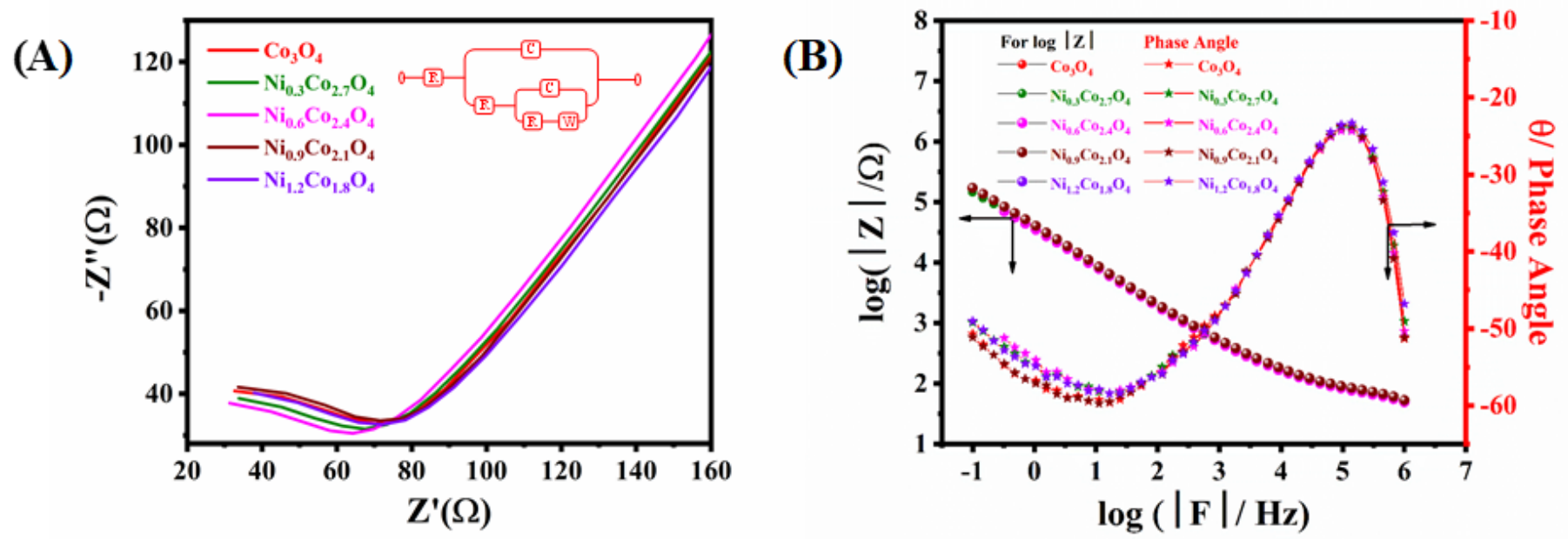

\section{Figure 4}

EIS analysis of all nickel cobalt oxide powders. (A) Nyquist plot (B) Bode plot of different nickel cobalt oxide powders with different $\mathrm{Ni}$ concentrations. (c) Equivalent circuit diagram.

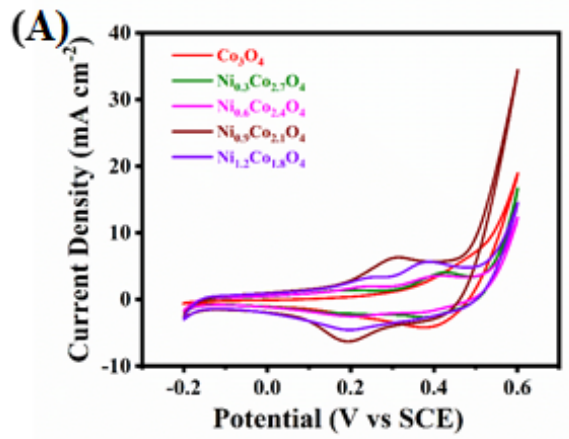

(B)

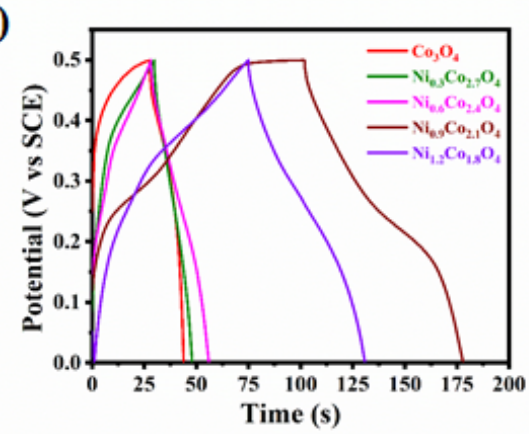

\section{(D)}

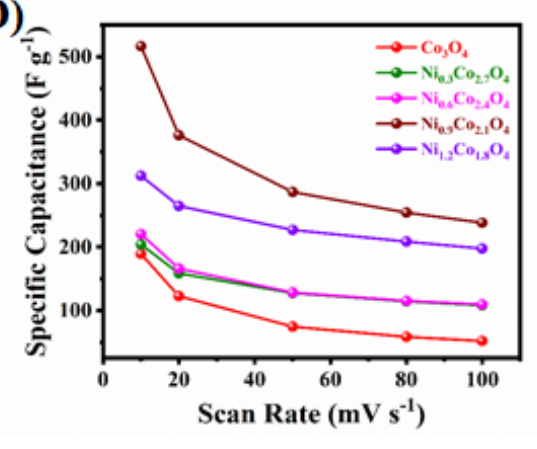

(E)

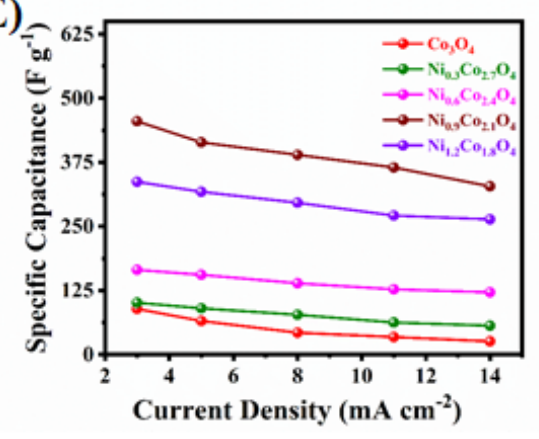

(C)

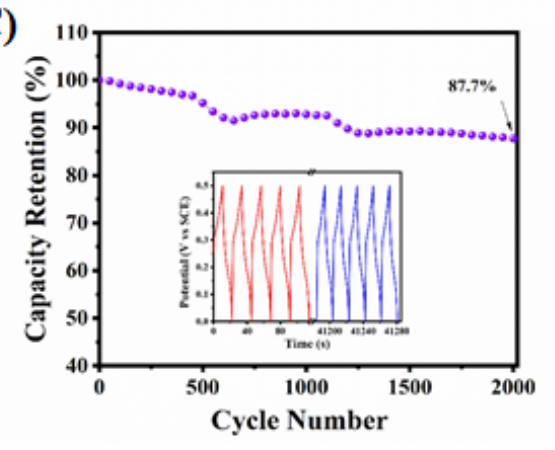

(F)

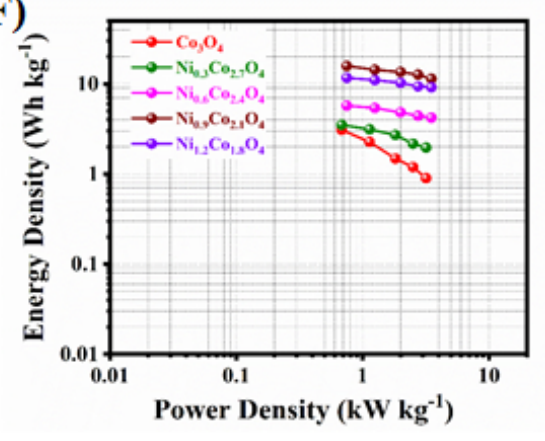

\section{Figure 5}

Supercapacitor study of nickel cobalt oxide powders with different Ni concentrations. (A) CVs of all nickel cobalt oxide electrodes on CC at $10 \mathrm{mV} \mathrm{s}-1$ scan rate. (B) GCD study of different prepared electrodes at 3 $\mathrm{mA} \mathrm{cm}-2$ current density. (C) Cyclic stability of electrodes prepared by using Ni0.9Co2.104 powder. Inset: First and last five cycles of GCD curves. (D) Estimated specific capacitance from CV vs. of scan rate. (E) 
Specific capacitance calculated from GCD curve vs. applied current density. (F) Regone plot of different nickel cobalt oxide electrodes.
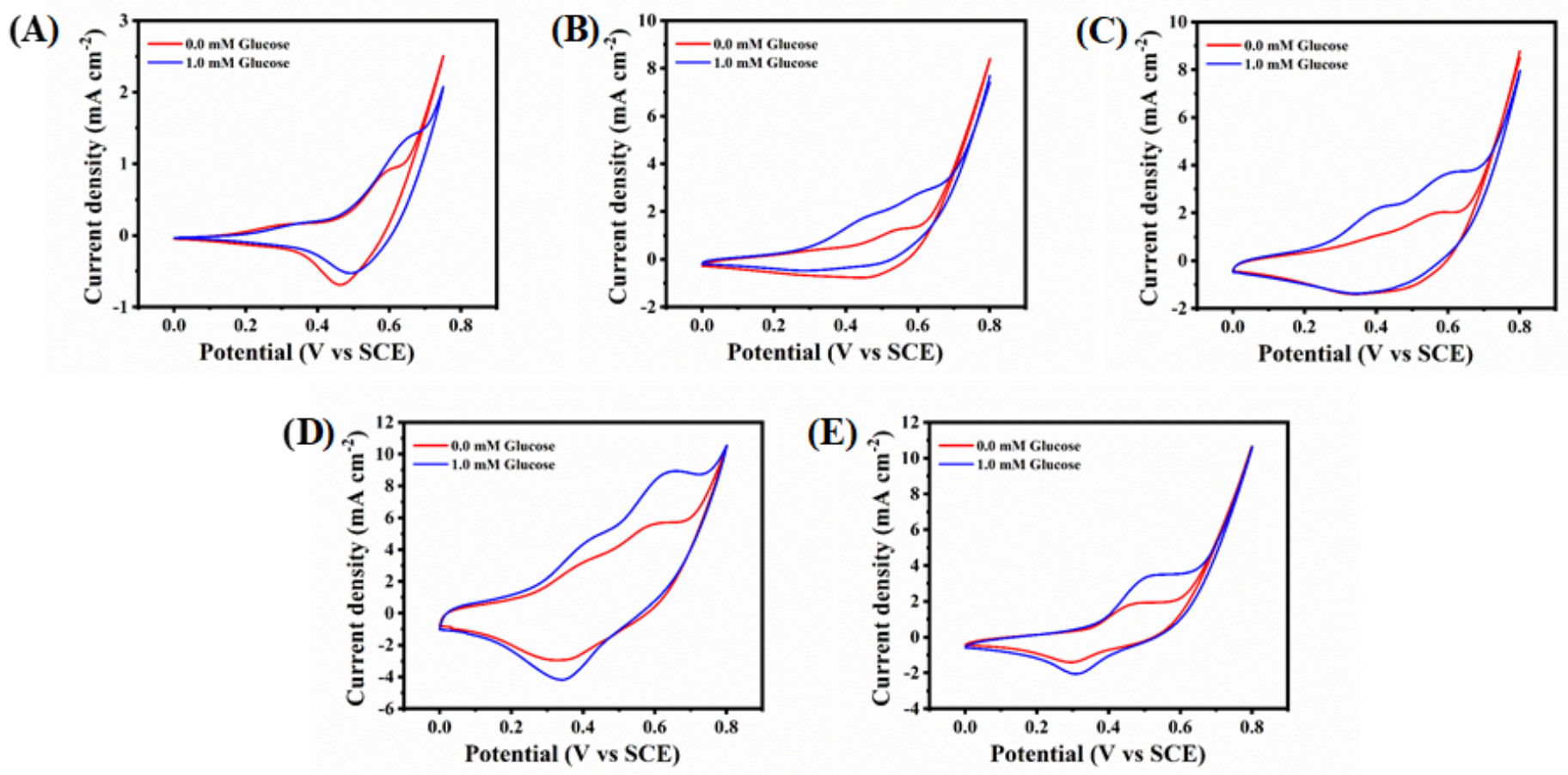

\section{Figure 6}

Behavior of different nickel cobalt oxide electrodes on CC with and without presence glucose. (A-E) CVs of $\mathrm{Co} 3 \mathrm{O} 4$, Ni0.3Co2.704, Ni0.6Co2.404, Ni0.9Co2.104, and Ni1.2Co1.804 electrodes, respectively, with and without the presence of glucose.
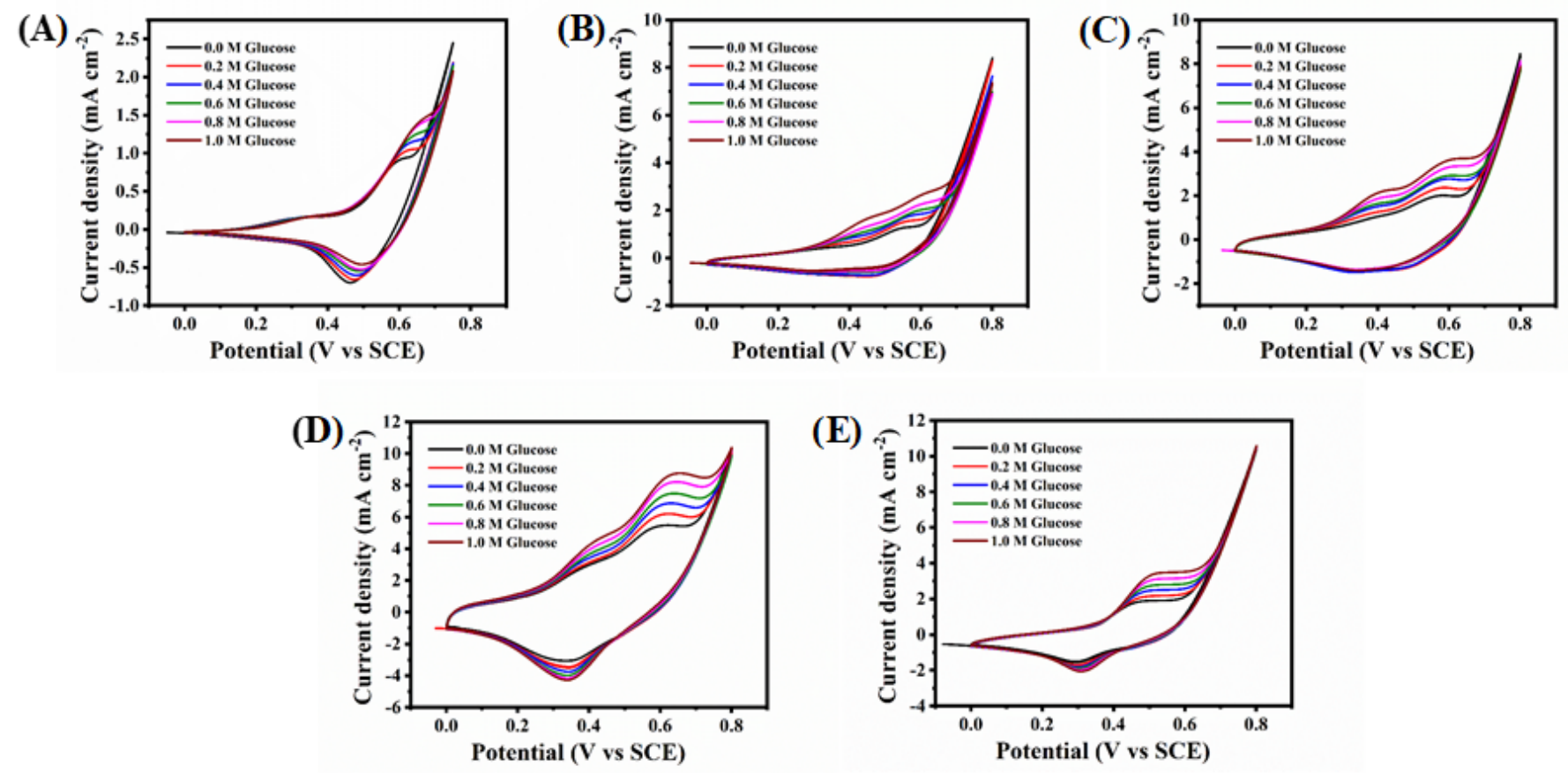
Figure 7

(A-E) CV curves of Co304, Ni0.3Co2.704, Ni0.6Co2.404, Ni0.9Co2.104, and Ni1.2Co1.804 electrodes at different concentrations of glucose at $100 \mathrm{mV} \mathrm{s}-1$.
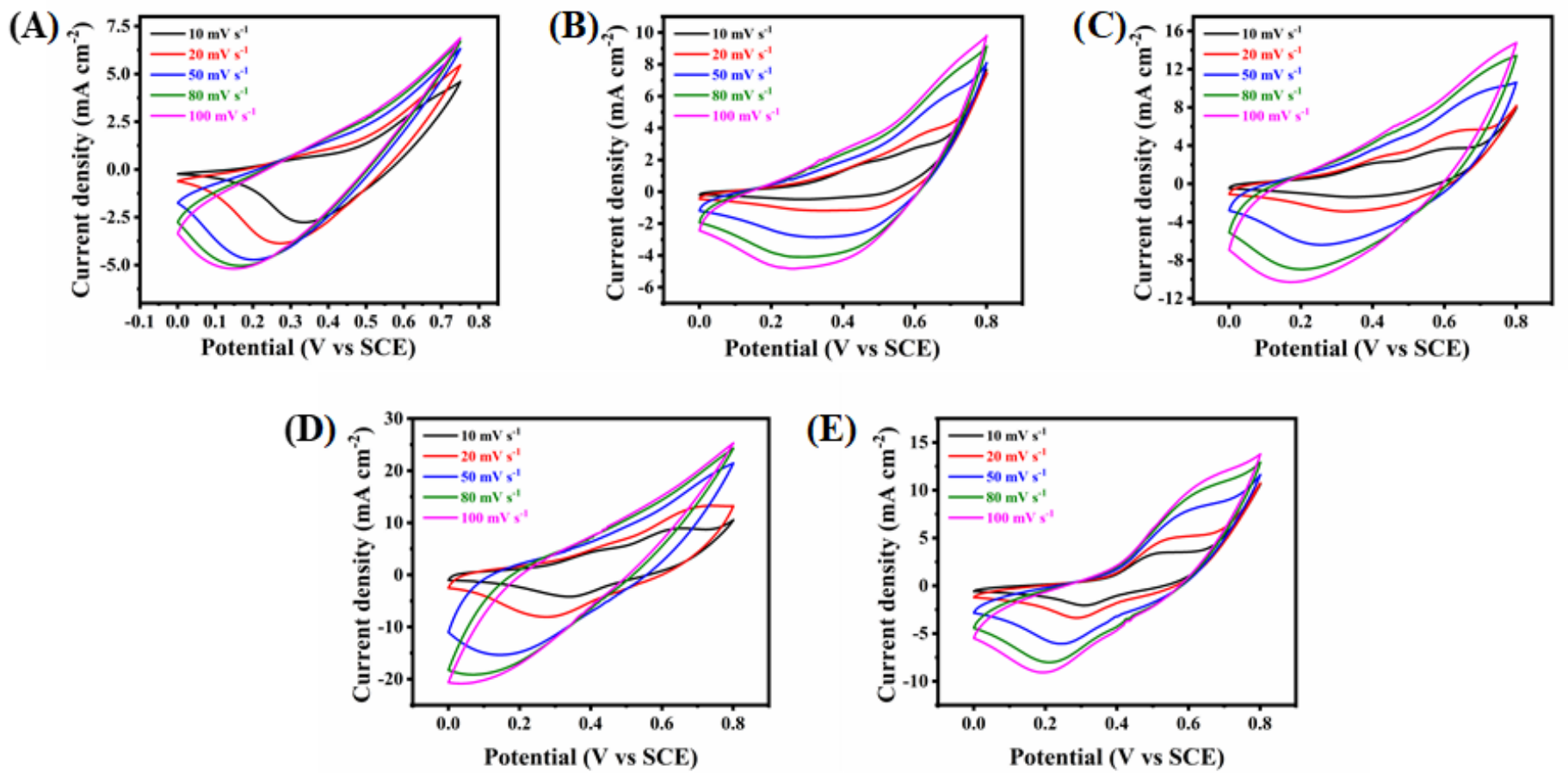

\section{Figure 8}

(A-E) CVs of Co3O4, Ni0.3Co2.704, Ni0.6Co2.404, Ni0.9Co2.104, and Ni1.2Co1.804 electrodes in the presence of $1.0 \mathrm{mM}$ glucose at 10 to $100 \mathrm{mV} \mathrm{s}-1$ scan rate.
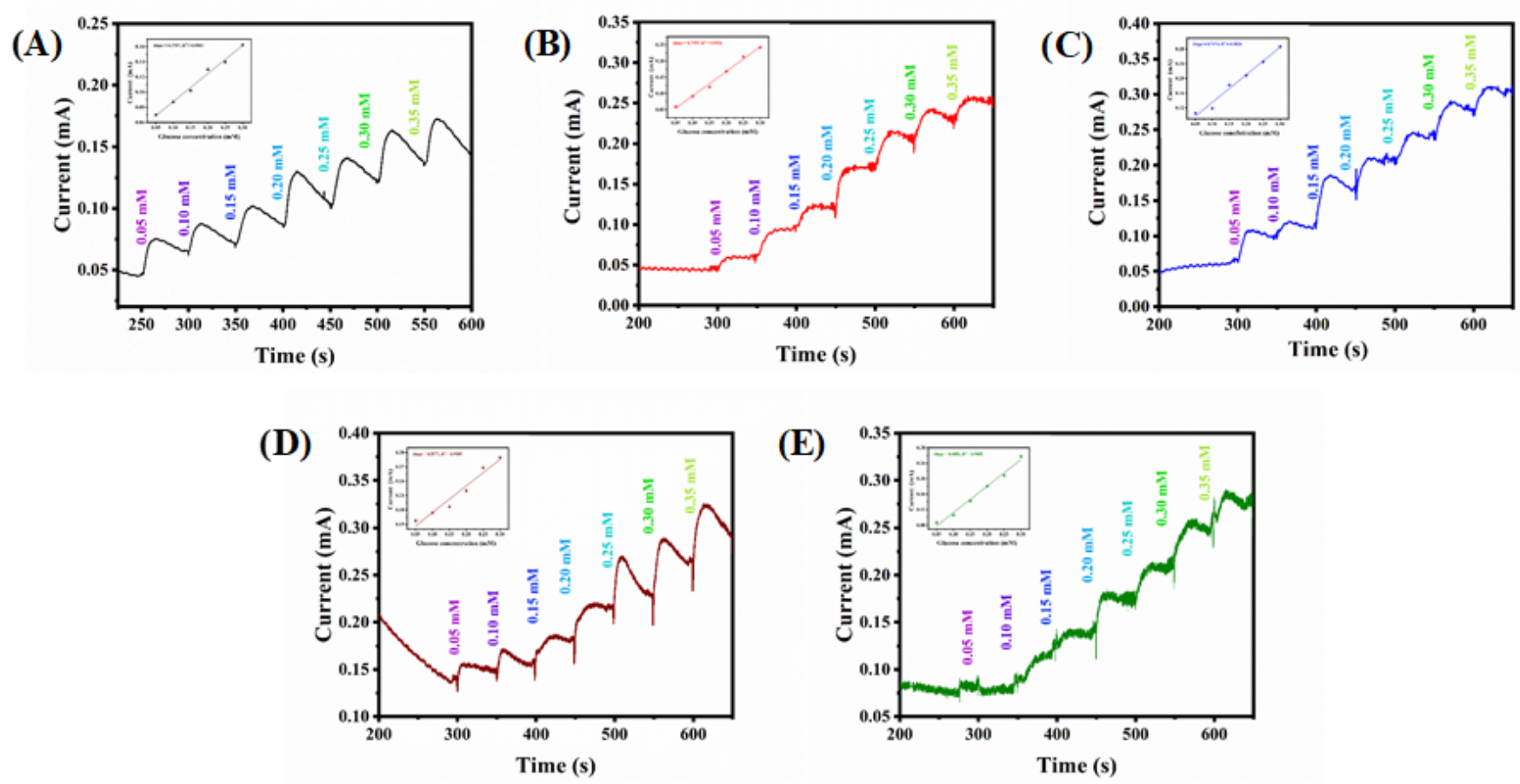


\section{Figure 9}

(A-E) Amperometric responses (I vs. t) of $\mathrm{Co} 3 \mathrm{O} 4, \mathrm{NiO} .3 \mathrm{Co} 2.704, \mathrm{Ni0} .6 \mathrm{Co} 2.4 \mathrm{O} 4, \mathrm{Ni0} .9 \mathrm{Co} 2.104$, and Ni1.2Co1.804 electrodes at a $0.5 \mathrm{~V}$ potential with the addition of $0.05 \mathrm{mM}$ glucose. Inset of each graph: calibration curves of chronoamperometric study]

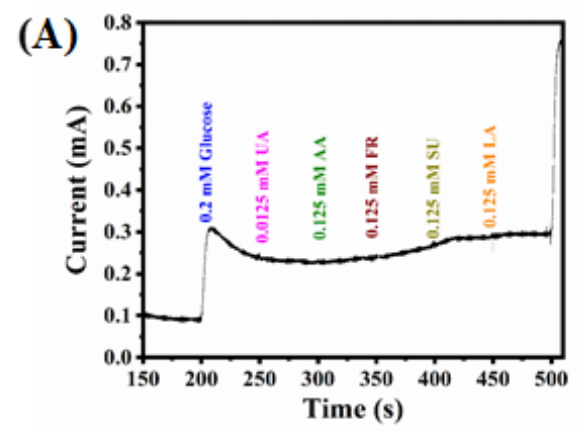

(B)

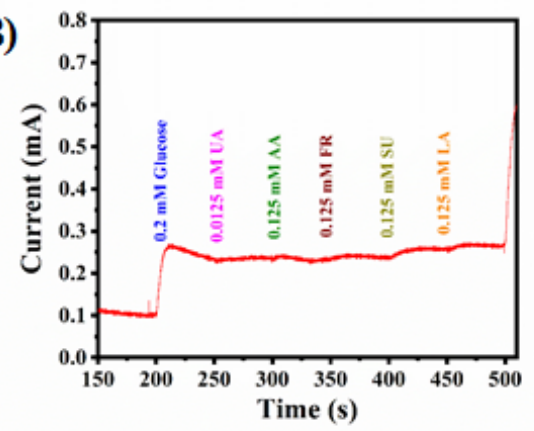

(C)

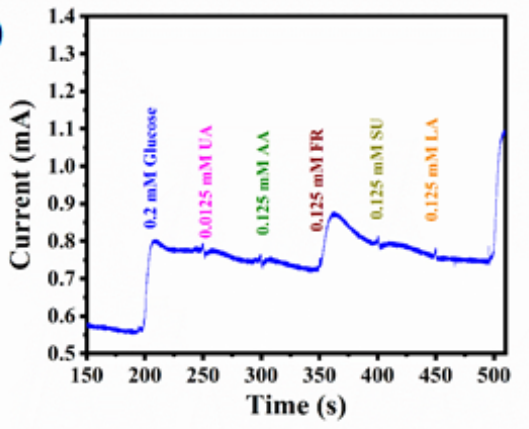

(D)

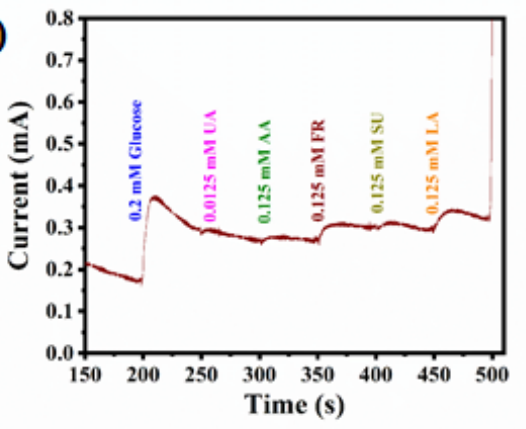

(E)

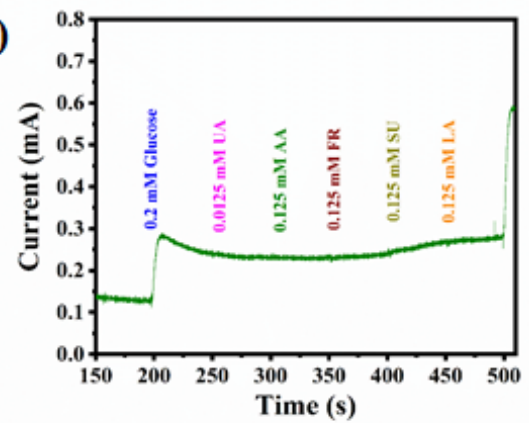

Figure 10

(A-E) chronoamperometry study of (I vs. t) of $\mathrm{Co304}$, Ni0.3Co2.704, Ni0.6Co2.404, Ni0.9Co2.104, and Ni1.2Co1.804 electrodes after successive addition of glucose and interference species [UA, AA, FR, SA, and LA].

\section{Supplementary Files}

This is a list of supplementary files associated with this preprint. Click to download.

- 2.Supplimentorydata.docx

- Tables.docx 